\title{
The Effect of Neuro-Linguistic Programming (NLP) on Reading Comprehension in English for Specific Purposes Courses
}

Fahimeh Farahani*

Department of Foreign Languages, Tehran University of Medical Sciences, Iran

Corresponding author: Fahimeh Farahani, Email: nina_farahani@yahoo.com

\begin{tabular}{l} 
ARTICLE INFO \\
\hline Article history \\
Received: October 07, 2017 \\
Accepted: January 29, 2018 \\
Published: January 31, 2018 \\
Volume: 6 Issue: 1 \\
\hline
\end{tabular}

Conflicts of interest: None

Funding: None

\begin{abstract}
Neuro-Linguistic Programming (NLP) has potential to help language learners; however, it has received scant attention. The present study was an attempt to investigate the effect of NLP techniques on reading comprehension of English as a Foreign Language (EFL) learners at an English for Specific Purposes (ESP) course. To achieve this goal, two intact classes of students were selected to form an experimental group $(n=30)$ and a control group $(n=30)$. A reading pretest (based on the course content) was given to all participants. The sensory learning styles of the participants were diagnosed using Reid's (1987) leaning style questionnaire, and the participants in the experimental group were familiarized with NLP techniques to be able to implement these techniques in their reading. In the control group, the conventional approach to teach ESP reading was used. Considering the analysis of posttest results through ANCOVA, it was found that implementation of NLP techniques can have significant effect on reading comprehension of Iranian undergraduate EFL learners. Pedagogical implications are discussed.
\end{abstract}

Key words: Neuro-linguistic Programming (NLP), English for Specific Purposes (ESP), Reading Comprehension, Iranian Undergraduate EFL Learners

\section{INTRODUCTION}

Reading comprehension is among the most significant language skills for the students at tertiary level. There is no doubt that most material presented to the university students is in form of written text, and those who have adequate reading comprehension ability can tackle the difficulty of reading texts (Hu, 2004).

Reading comprehension also plays a significant role in English for Specific Purposes (ESP) language courses. Much of learning material is also presented to the language learners in ESP courses in the written form, and they should be able to read the text to comprehend it. However, as a number of problems exist in ESP courses in the context of Iran, the outcome of these courses has not been promising (Amirian \& Tavakoli, 2009). In the first place, most learners who attend ESP courses wish to improve their Speaking skill; therefore, little attention is accorded to reading comprehension. On the other hand, although most materials presented to the learners are in the written form, they are usually used to teach content vocabulary to language learners and do not serve the purpose of reading comprehension (Akbari \& Tahririan, 2009). Moreover, learners' preferences and learning styles are not considered by the educators, and their potential effect is ignored (Isazadeh, Makui, Ansarian, 2016; Wang, Wang \& Huang, 2008).

Recent research has also shown that Neuro Linguistic Programming (NLP) has helped the problem of language learning in many contexts. NLP involves not only the use of language but also behavior and strategic thinking in the learning process. The combination of strategic thinking, behavior and language together is more likely to result in effective language learning compared to focusing on language alone. As a result, learners can get into the deep structure of a task. Baker and Rinvolucri (2005) introduce NLP as "a complex set of beliefs, skills and behaviors that can help a person communicate more accurately, effectively and respectfully" (p.4). Richards and Rogers (2000) note that along many language teaching methods which rely on the language learners' intelligence, including the Silent Way, Suggestopedia, and the use of NLP in language classes, the last one has received scant attention. Therefore, the main objective of this study was to find out whether or not utilization of NLP can solve the reading comprehension problem of language learners in ESP courses in the context of Iran. Focus was mainly accorded to students at ESP course which is among compulsory, and cumbersome courses for these students. The possible outcome of this study could also guide other educators who conduct similar courses in other medical schools in Iran.

\section{Research Question}

To pursue the purpose of the study, the following research question was proposed: 
- What is the effect of implementing NLP techniques on reading comprehension of Iranian undergraduate EFL learners in ESP courses?

\section{Theoretical Framework}

The researcher's main interest in this study was to find out the extent to which NLP can affect the reading comprehension of Iranian undergraduate EFL learners at ESP courses. Therefore, the researcher selected "the 4 pillars of NLP" theory as explained by Revell and Norman (1997, as cited in Richards \& Rodgers, 2000). They categorized 4 key elements for NLP as shown in Figure 1.

In order to operationalize this theory, the researcher took into consideration a number of issues in designing the reading tasks. First of all, the main objective (outcome) of the task was made clear. Secondly, the reading tasks were conducted cooperatively in order to maximize similarities between learners. It also helped minimizing the differences, especially at non-conscious level. Thirdly, learners were asked to pay attention to reading techniques used by other peers in the class as a possible approach to solving reading questions. This is a conscious and nonverbal step in the task. Fourthly, leaners were briefed on the task and were asked to be flexible and move from one reading strategy to another in case they found the strategy ineffective. This had to be repeated until the desired outcome was achieved.

Another theory which formed the basis of this study was The Zone of Proximal Development (ZPD) as suggested by Vygotsky (1987, as cited in Chaiklin, 2003). ZDP is based on the effect of cooperation in learning. It is assumed that learners should enter other peers' proximal zone in order to learn effectively. The ZDP of a person is his/her area of expertise from which others can benefit. It is also known as the aided Zone. As one aspect of NLP is cooperation, it is assumed that learners can enter each other's proximal zone through NLP and benefit from more resources of knowledge.

\section{LITERATURE REVIEW}

\section{A Synopsis of NLP history}

NLP is among recent developments in science which connects mathematics to language and neurology. The prosecutors on NLP were of various backgrounds, Bandler was a Mathematician and Grinder was a linguist who suggested

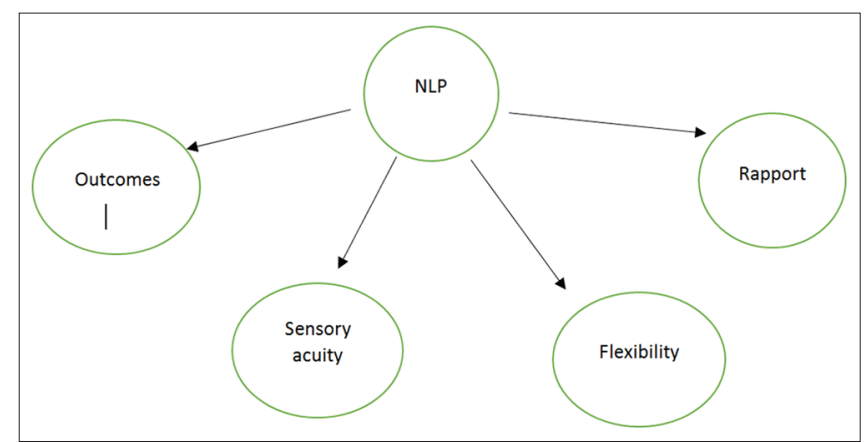

Figure 1: Four key elements of NLP (designed by the researcher based on Revell and Norman, 1997)
NLP in 1970s (Bandler \& Grinder, 1975). They incepted NLP to level interpersonal and intrapersonal communication between and among people (Revell \& Norman, 1997). To achieve this purpose a set of techniques and patterns were created by scholars to attempt to develop NLP. Winch (2005) named these patterns "the strategies that other people can use in the pursuit of excellence"(p.1).

According to Tosey and Mathison (2003), NLP has the potential to be used as a theory in the field of education. He assumes that not only is NLP a whole-body learning theory which fosters interpersonal and intrapersonal communication, but also is it cooperative and goal-oriented. Later NLP was used as a training procedure in training managers, trainers, sales people, market researchers, counsellors, consultants, medics, lawyers and more. Currently, NLP is used as the underlying assumption in U.K. it is being applied through "NLPEdNet" software.

Richards and Rodgers (2000) were among the scholars who discussed the use of NLP in language education. They built upon the notion of NLP discussed by Bandler and Grinder (1975) and looked at it as " how people influence each other and in how behaviors of very effective people could be duplicated" (Richards \& Rodgers, 2000, p.125). Later they asserted that although NLP can have effect on language learning, scant research has dealt with this issue.

\section{Reading Comprehension}

RAND Reading Study Group (2002) defines reading comprehension as "the process of simultaneously extracting and constructing meaning through interaction and involvement with written language" (p. 11). They present three elements for reading comprehension: "1) The reader who is doing comprehending, 2) the text that is to be comprehended, 3) the activity in which comprehension is a part" (p. 11). They further state that three elements define reading comprehension as a phenomenon that occurs within a large socio-cultural content that shapes and is shaped by the reader that interacts with each of the three elements. They further mentioned that understanding requires acknowledging that it is a cognitive, linguistic, and cultural activity.

According to Burns, Roe, and Ross (1999), different categories of comprehension are used by the readers to understand the message of the writer: "literal comprehension" and "higher-order comprehension" (p. 219). "To take in idea that is directly stated is literal comprehension; this is the most basic type" (Burns et al., 1999, p. 219). They further mentioned that Higher-order reading comprehension goes beyond literal understanding of a text. It involves higher-order considering processes. Higher-order reading comprehension includes: "interpretive reading", "critical reading", and "creative reading". "Interpretive reading is reading between the lines or making inferences. It is the process of deriving ideas that are implied rather than directly stated" (Burns et al., 1999, p. 227). Readers infer the implied information by combining the information in the text with their background knowledge of the world. 


\section{ESP Reading}

Several lines are written on the vitality of devising ESP courses. Lorenzo (2005) suggests that ESP "concentrates more on language in context than on teaching grammar and language structures" (p. 1). The context in the majority of cases is related to learners' occupation which is intensely motivating for them. In a study conducted by Alemi and Ebadi (2010) on the effectiveness of pre-reading activities on ESP reading concluded that ESP course learners have knowledge of their field and book authors have knowledge of language. Both should be mingled to increase the success of ESP reading courses.

It is worth mentioning that with ample developments in different economic and social contexts a macro environment has been provided ESP teaching and learning with new tendencies in ESP teaching fashions. As Spector-Cohen, Kirschner, and Wexler (2001) reveal, teachers and curriculum designers should find out how learners solve problems in reading rather than deciding what is problematic in reading texts in a foreign language. This way, insights into cognitive strategies for teaching would be discovered.

Many of the studies that have been conducted on the effect of using NLP tasks on reading comprehension have dealt with increasing machine responses of the software to answer reading questions. For example, Baalbaki and Zylberglejd (n.d.) studied the effect of NLP tasks on answering reading questions by a software and found the tasks to be effective. In another study, Arivuchel Van, and Lakahmi (2017) conclude that NLP is a possible approach to increase reading ability of computerized systems. However, studies dealing with the effect of NLP instruction in language classes on reading comprehension of the language learners is extremely scant.

\section{METHOD}

\section{Research Design}

This is an experimental study with a between-subject design, as the performance of participants in two distinct groups is compared to seek the answers to research questions. The main independent variable in the study is the effect of NLP and the dependent variable is reading comprehension of the Iranian undergraduate EFL learners. In addition and due to the quantitative nature of this research, pragmatism best describes the philosophy of the researcher and conclusions were drawn based on observable data.

\section{Participants}

To fulfill the goal of this study, 60 undergraduate students majoring in medical sciences took part in the study. These participants were of different genders and their age ranged between 19 and 21. The participants took part in the study in form of two intact classes; therefore, non-random sampling through the convenience approach can best describe the participants' sampling procedure in this study. These participants formed two cohorts for this study, i.e. an experimental group $(n=30)$ and a control group $(n=30)$. Table 1 reveals the demographics of the participants.
These participants in these two classes were assigned to an experimental group $(n=30)$ and a control group $(n=30)$. Their homogeneity in terms of reading was determined through a reading comprehension test. In order to make sure the groups were homogeneous, an analysis of covariance was run using pre-tests data. It showed that there was no significant difference between two groups in terms of reading comprehension prior to treatment.

\section{Instruments and Materials}

The materials used in the present study included ten passages, taken from 'Reading Science and Medicine in English' authored by Kamyab, Mahboubi, Seddigh, Shokrpor (2016) which is a reference book in the target discipline. The participants were given a pretest (from the above mentioned book), as pretest, and another test from the book as posttest. The instruments used in the study included: a) Reading pretest and posttest, and b) Reid (1987) learning style questionnaire. The reliability of the reading pretest and posttest was checked using Cronbach Alpha and was equal to.89, and.88 for the two tests respectively. In addition, these tests are considered valid, as they are designed by a panel of experts at the University of Tehran, and are used to measure learners' reading comprehension at ESP courses. The researcher also checked the reliability of the results gained from Reid's learning style questionnaire $(\alpha=.79)$.

\section{Data Analysis Metho}

The main objective of this study was to find out whether there is any statistically significant difference between the experimental and control group concerning the treatment of the study. Based on the fact that the control and experimental groups were two intact classes of medicine students, and might not be matched at the outset, the pretest scores (the covariant) was adjusted and an analysis of covariance, ANCOVA was applied to find if there was any preexisting significant difference in pre-tests of both experimental and control group to ensure the homogeneity of the groups from the very beginning so that any significant difference in control and experimental group can be attributed to the effect of the treatment. Here it is worth mentioning that all the assumptions for applying ANCOVA to the data was investigated to meet the conditions under which ANCOVA is permitted to be applied.

\section{Procedure}

The treatment phase in the experimental group was based upon a series of topics, each presented in one of the ten sessions. The topics were among the most popular issues in relation to NLP practices. Listed below:

1. Introduction; NLP presuppositions and core concepts

2. Goal Setting (Outcome)-Guided Fantasy

3. Sensory Language (Reid's Test)

4. Sensory Language (Continue)

5. Metaphor- Accentuate the Positive

6. Emotion 
Table 1. Demographics of the Participants

\begin{tabular}{|c|c|c|c|c|c|c|}
\hline Group & $\mathbf{N}$ & Gender & Proficiency level & Language learning experience & ethnicity & Age \\
\hline Experimental & 30 & $\begin{array}{l}14 \text { male } \\
16 \text { female }\end{array}$ & Intermediate & $\begin{array}{l}\text { Average } \\
24 \text { months }\end{array}$ & Iranian & $19-20$ \\
\hline Control & 30 & $\begin{array}{l}12 \text { male } \\
18 \text { female }\end{array}$ & intermediate & $\begin{array}{l}\text { Average } \\
22 \text { months }\end{array}$ & Iranian & $19-21$ \\
\hline
\end{tabular}

\section{Belief (Flexibility)}

8. There is no Failure; only Feed back

9. Finding the Best Strategy (Flexibility)

10. Review of the strategies

The participants in the experimental group were familiarized with each of the abovementioned techniques in one session. They were guided on how to set objectives, what learning styles are, how to learn language by using human senses, the role of emotion in learning languages, and various strategies they could implement to facilitate their learning through using senses. The presentation of each technique was followed by reading a medical text and answering the questions which followed the text. After taking VAK (1997) learning style test, the teacher (researcher) asked the participants to read the text and answer the questions that followed. The questions were related to the presented NLP material, especially the sensory language. Now that the participants knew their sensory style, they were asked to read the text using their own style. For example, one who was visual (according to the test) attempted to use visual aids in comprehending the text, such as glosses, covering visual clue, boldness of words, Italic forms, headings, etc. Auditory learners could read the text aloud to him/herself, or listen to the audio material, or possibly have background music while reading the text. Kinesthetic ones were asked to do activities of moving their hands, and writing down information. They were also allowed to stand up and walk for some seconds if they would feel better, or even role-play the text for themselves.

The participants in the control group underwent the traditional method of teaching the reading texts. They were taught scanning and skimming reading techniques. Finally, a reading posttest was assigned to both groups. The posttest consisted of 20 multiple choice questions. Both groups took the posttest for reading. The results were then analyzed using SPSS software.

\section{RESULTS}

Statistical Package in Social Sciences (SPSS) version 22 was used to analyze the data. Based on the objectives of the study, the following research question was addressed:

What is the effect of NLP on reading comprehension of Iranian undergraduate EFL learners in ESP courses?

Due to the fact that the participants of the study were in two intact classes of ESP, experimental and control group, the study was designed as quasi-experimental. In addition, meticulously defining many of the numerous variables involved in most applied linguistics research is quite a demanding task. One can hardly be certain that some specific treatment involves just that treatment and no other aspect of language learning or behavior. Nor can we be sure that the methods used are exclusive and the treatments really never overlapped. In the current study, the independent variable was considered as teaching methodology with two levels (with and without NLP), and the dependent variable was the measure of undergraduate medical students' reading comprehension.

The main objective of this study was to find out whether there is any statistically significant difference between the experimental and control group concerning the treatment of the study. Based on the fact that the control and experimental groups were two intact classes of medicine students, and might not be matched at the outset, the pretest scores (the covariant) was adjusted and an analysis of covariance, ANCOVA was applied to find if there was any preexisting significant difference in pre-tests of both experimental and control group to ensure the homogeneity of the groups from the very beginning so that any significant difference in control and experimental group can be attributed to the effect of the treatment. Here it is worth mentioning that all the assumptions for applying ANCOVA to the data was investigated to meet the conditions under which ANCOVA is permitted to be applied.

\section{Exploratory Data Analysis Results}

To make sure that parametric tests are suitable to be used in this study, there are two main assumptions; the normality of data distribution, and the homogeneity of variances. Table 2 shows the frequency and descriptive statistics for pretest scores.

According to Table 2, the mean and standard deviation of pre-test distribution is reported. The skewedness of the scores in NLP group is.385, and for control group.,116 and the kurtosis for NLP and control group is.519, and.523, respectively. According to Pallant (2011), when the skewedness, and kurtosis indexes are less than one, the normality of scores is proved. Also according to the table, the skewedness of the scores in NLP group is.129, and for control group.,641, respectively proving the normality of scores (Pallant, 2011). The observed mean of experimental group (NLP), is 16.57, while it is 13.93 for the control group.

\section{Inferential Statistics}

In order to statistically adjust the means for posttest scores for any initial difference between the groups on the pre-test, an analysis of covariance (ANCOVA) was applied to the scores. The ANCOVA technique removes the portion of each participant's posttest score which is in common with his or 
her pretest score. The report of the analysis of covariance is in Table 3. Prior to that, as mentioned earlier, one of the assumptions to apply ANCOVA is the equality of variances. Table 3 shows the measurement of equality of variances for the dependent variable, posttest.

The results of the Levene's test for the posttest $(\mathrm{F}=.368$, $\mathrm{df}=1,58, p=.546>.05)$ showed no significant difference between the variances of the two groups and thus the second assumption was also met.

The statistical significance value ( $\rho$-value) is reported to be. 000 which shows a statistically significant difference between the adjusted means $(\rho<.0005)$. Therefore, it can be concluded that NLP reading techniques have significant effect on reading comprehension of Iranian undergraduate EFL learners at ESP course.

Later, post-hoc comparison was conducted to report where the difference lies. Table 4 shows the results of pairwise comparison.

As seen from Table 4, the results of pairwise comparison show the significant difference between the control and experimental group of this study $(\mathrm{p}=.000<.05)$ leading to reject the null hypothesis which stated that there is no statistically significant difference between the means of experimental and control group, proving that the treatment was effective.

Table 2. Descriptive Statistics for Pretests

\begin{tabular}{lcccc}
\hline & $\begin{array}{c}\text { NLP } \\
\text { Pretest }\end{array}$ & $\begin{array}{c}\text { Control } \\
\text { Pretest }\end{array}$ & $\begin{array}{c}\text { NLP } \\
\text { Posttest }\end{array}$ & $\begin{array}{c}\text { Control } \\
\text { Posttest }\end{array}$ \\
\hline Mean & 12.67 & 12.63 & 16.57 & 13.93 \\
Std. Deviation & 2.294 & 2.470 & 1.870 & 2.625 \\
Skewness & 0.385 & 0.116 & -0.129 & 0.641 \\
Kurtosis & -0.519 & -0.523 & -0.837 & -0.452 \\
\hline
\end{tabular}

\section{DISCUSSION}

The ultimate goal of the present study was to investigate the effect of NLP on Iranian undergraduate EFL learner' reading comprehension. The results showed a statistically significant difference between experimental and control group learners in terms of posttest reading comprehension which means that implementing NLP tasks (increasing participants of NLP strategies) is an effective approach to improving their reading skill. This was mostly done by 1 ) informing the participants of their sensory learning styles, and 2) instructing reading strategies related to the learners' learning styles.

Alongside with the researcher's coming up with a significant difference between the two teaching methods in terms of their effect on ESP reading comprehension, the value of NLP methods is undeniable. In other words, NLP proved to be an effective means of improving learning language in general and language skills in particular. As most of NLP techniques such as mind-mapping and goal setting are metacognitive strategies, the effect of these strategies on reading comprehension has been promising. Results of a study conducted by Siriphanich and Laohawiriyanon (2010, as cited in Hariri \& Tahriri, 2013) indicated the significant effect of mind-mapping on improving the performance of reading comprehension of EFL learners in Taiwan. Other study by Arivuchel Van and Lakahmi (2017) had revealed that NLP can increase reading performance of computerized systems. Arivuchel Van and Lakahmi (2017) had also urged the need for investigating the effect of NLP on reading comprehension of the language learners.

NLP as an important concept in humanistic psychology deals with the art of communication and the study of the structure of subjective experience (Tosey, Mathison, \& Michelli, 2005, as cited in Pishghadam, Shayesteh, Shapoori, 2011 , p. 909). As a result, the researcher attempted to pro-

Table 3. Tests of Between-Subjects Effects

\begin{tabular}{lcccccc}
\hline Source & Type III Sum of Squares & df & Mean Square & F & p & Partial Eta Squared \\
\hline Corrected Model & $154.018 \mathrm{a}$ & 2 & 77.009 & 16.975 & 0.000 & 0.373 \\
Intercept & 378.423 & 1 & 378.423 & 83.417 & 0.000 & 0.594 \\
pretest & 0.418 & 1 & 0.418 & 0.092 & 0.763 & 0.002 \\
Teaching*method & 153.541 & 1 & 153.541 & 33.846 & 0.000 & 0.373 \\
Error & 258.582 & 57 & 4.537 & & & \\
Total & 12682.000 & 60 & & & & \\
Corrected Total & 412.600 & 59 & & & &
\end{tabular}

a. R Squared $=0.373$ (Adjusted R Squared $=0.351$ )

Table 4. Pairwise Comparisons

\begin{tabular}{|c|c|c|c|c|c|c|}
\hline \multirow[t]{2}{*}{ (I) teaching method } & \multirow[t]{2}{*}{ (J) teaching method } & \multirow[t]{2}{*}{ Mean Difference (I-J) } & \multirow[t]{2}{*}{ Std. Error } & \multirow[t]{2}{*}{$\mathbf{p}$} & \multicolumn{2}{|c|}{$\begin{array}{l}\text { 95\% Confidence Interval } \\
\text { for Difference }\end{array}$} \\
\hline & & & & & $\begin{array}{l}\text { Lower } \\
\text { Bound }\end{array}$ & $\begin{array}{l}\text { Upper } \\
\text { Bound }\end{array}$ \\
\hline NLP & Control & $3.218^{*}$ & 0.553 & 0.000 & 2.110 & 4.326 \\
\hline Control & NLP & $-3.218^{*}$ & 0.553 & 0.000 & -4.326 & -2.110 \\
\hline
\end{tabular}


vide the participants in the NLP group with an environment in which they could experience the world surrounding them through their senses and helped them not only to gain awareness of their learning styles, but also to create their own personal ways.

One of the reasons contributing to the effect of NLP instruction on reading comprehension of the medical students in this study may be awareness of the learning style. Wang, Wang, and Huang (2008) report that language learners need to know their learning styles so that they can adjust their learning strategies with their learning styles.

Furthermore, improving NLP strategies in a learning context can help learners to be equipped with strategies designed to instill positive attitudes toward learning and positive views of themselves as learners. When learners are empowered with NLP strategies in tandem with learning strategies, they will have more awareness of the learning process in their mind. Thus, NLP strategies are being widely emphasized in all domains of, English Language Teaching, ESP included. Tosey and Mathison (2006) assert, "NLP has achieved considerable popularity as an approach to communication and personal development. It is getting increasingly popular in professional arenas of education, management training and coaching. However, there is little academic work to date on this innovative field of practice" (p. 1). In the context of current research studies have demonstrated significant impact of NLP approaches on various aspects of language learning. In spite of all the numerous lines written and training courses held on NLP strategies, there are still a few sources that provide the teachers and learners of English language with NLP strategies used in teaching the skills and subskills of the language, especially, ESP settings.

This study can also have pedagogical implications for language teachers who wish to increase their learners' reading ability in ESP courses. It is also suggested that the reading materials used in ESP classes should be equipped with various visual, audio and kinesthetic aids such as audio and visual glosses.

\section{CONCLUSION}

Considering that Iranian undergraduate EFL learners have insufficient reading comprehension of ESP reading materials, this study made use of NLP instruction to enhance their reading. The results of the study revealed that NLP instruction can be effective in terms of reading comprehension for Iranian undergraduate EFL learners at ESP courses. The results gained from this study can have pedagogical implications for language teachers who may wish to increase their learners reading comprehension. In addition this research can be a guide to other researchers who may wish to gauge the effect of NLP instruction of other performance of the EFL leaners with regard to other language skills.

\section{REFERENCES}

Akbari, Z., \& Tahririan, M. H. (2009). Vocabulary learning strategies in an ESP context: The case of Para/med- ical English in Iran. The Asian EFL Journal Quarterly, 11(1), 39-61.

Alemi, M., \& Ebadi, S. (2010). The Effects of pre-reading activities on ESP reading comprehension. Journal of Language Teaching \& Research, 1(5), 569-577.

Amirian, Z., \& Tavakoli, M. (2009). Reassessing the ESP courses offered to engineering students in Iran. English for specific purposes world, 8(23), 1-13.

Arivuchel Van, K. \& Lakahmi, K. (2017). Reading comprehension system-A review. Indian J. Sci. Res, 14(1), 83-90.

Baker, J. \& Rinvolucri, M. (2005). Neuro-Linguistic programming. English Teaching Professional, 37, 4-6.

Baalbaki, W., \& Zylberglejd, D. (n.d). CS224N: Natural Language Processing with Deep Learning Reading Comprehension. retrieved on 12, Feb, 2018, from https://web. stanford.edu/class/cs224n/reports/2718305.pdf

Bandler, R. \& Grinder, J. (1975). The Structure of Magic I: a book about language and therapy. Palo Alto, California: Science and Behaviour Books, Inc.

Burns, P. C., Roe, B. D., \& Ross, E. P. (1999). Teaching reading in today's elementary schools. Boston: Houghton Mifflin.

Chaiklin, S. (2003). The zone of proximal development in Vygotsky's analysis of learning and instruction. $V y$ gotsky's educational theory in cultural context, 1, 39-64.

Hariri, M. \& Tahriri, A. (2013). EFL learners' attitudes towards using mind mapping technique in their reading comprehension. Modern Journal of Language Teaching Methods, 3(1), 39- 47.

$\mathrm{Hu}, \mathrm{Y}$. (2004). The cultural significance of reading instruction in China. The Reading Teacher, 57(7), 632-639.

Isazadeh, P., Makui, S. M. Z., \& Ansarian, L. (2016). Effect of instructional vs. authentic video materials on introvert and extrovert Iranian EFL learners' vocabulary learning. International Journal of Education \& Literacy Studies, 4(4).

Kamyab, G. H., Mahboubi, A., Seddigh, F. Shokrpor, N. (2016). Reading Science and Medicine in English. Fars, Iran: Ide Derakhshan Publication

Lorenzo, F. (2005). Teaching English for specific purposes. UsingEnglish.com. Retrieved October, 2017 from http:// www.usingenglish.com/teachers/articles/teaching-englishforspecific-purposesesp.html

Pallant, J. (2011). SPSS survival manual (3 ${ }^{\text {rd }}$ ed.). NY: Open University Press.

Pishghadam, R., Shayesteh, S., \& Shapoori, M. (2011). Validation of an NLP scale and its relationship with teacher success in high schools. Journal of Language Teaching and Research, 2(4), 909-917. Retrieved on October 23, 2017, from http://www.ojs.academypublisher.com

RAND Reading Study Group. (2002). Reading for understanding: Toward an $R \& D$ program in reading comprehension. Santa Monica, CA: RAND Education. Retrieved December 18, 2017, from http://www.rand.org/ pubs/monograph_reports/2005/MR1465.pdf

Revell, J., \& Norman, S. (1997). In your hands: NLP in ELT. London, England: Saffire Press. 
Richards, J. C., Rodgers, T. S. (2000). Approaches and methods in language teaching. Oxford; Oxford University Press.

Spector-Cohen, E., Kirschner, M., \& Wexler, C. (2001). Designing EAP reading courses at the university level. English for Specific Purposes, 20(4), 367-386.

Tosey, P., \& Mathison, J. (2003). Neuro-linguistic programming: Its potential for learning and teaching in formal education.

Tosey, P., \& Mathison, J. (2006). Introducing Neuro-linguistic Programming. Retrieved on Dec 11, 2017 from
Www.som.surrey.ac.uk/NLP/Resources/Introducing NLP.pdf.

Wang, T. I., Wang, K. T., \& Huang, Y. M. (2008). Using a style-based ant colony system for adaptive learning. Expert Systems with Applications, 34(4), 2449-2464.

Winch, S., (2005). From Frustration to Satisfaction: Using NLP to Improve Self Expression. Retrieved on Dec 12, 2017 from http://www.englishaustrailia.com.au/ index.cgi 